\title{
AN INTERNATIONAL SYMPOSIUM ON INSTRUCTION IN THE MECHANICS OF FLUIDS
}

\section{SYMPOSIUM INTERNATIONAL SUR L'ENSEIGNEMENT DE LA MÉCANIQUE DES FLUIDES}

\section{FLUID MECHANICS \\ IN GERMAN ENGINEERING EDUCATION}

BY EDUARD NAUDASCHER *

In spite of the intense public debate on the urgency of educational reforms in Germany, the break from tradition proceeds at an extremely slow pace. The consequences are as evident in hydraulics and fluid mechanics as in many other discipline. Paradoxically, in the very country in which modern fluid mechanics had its origin, when Prandtl overcame the divergence of experimental hydraulics and theoretical hydrodynamics, the empirical approach if not also the purely mathematical is still to be found in the most unadulturated form. Civil engineers and a number of mathematicians continue to treat and teach fluid-flow phenomena much as before the advent of fluid mechanics, and there still exists virtually no contact between them. Mechanical engineers are an exception; yet even their achievements in fluid mechanics have clearly been handicapped by the obsolete features of the educational system.

One of the greatest obstacles to progress in the higher education of engineers in Germany has probably been the strong orientation of the institutes of technology toward professional practice. It is significant to note that Prandtl established

* Institute of Hydraulic Research. The University of Iowa, Iowa City (Iowa). his school at a university, where he was free to develop a more fundamental approach to engineering education and research. Only with the founding of new universities is the inclusion of engineering sciences in university programs Iosing its uniqueness, and only in the past year has the separate identity of the institutes been formally abolished by their newly acquired university titles. Nevertheless, the traditional emphasis on practice and the priority of applied research, which was essential during the war and ensuing economic rehabilitation, still have a noticeable influence on the teaching of engineering sciences. Whereas in the United States it became more and more common to leave the instruction in the various facts and procedures of engineering practice to introductory courses and let experience be gained on the $\mathrm{job}$, in Germany the engineering graduates are still expected to be immediately effective in their first employment. As a consequence, courses on fluid motion are, on the whole, designed to give the bare minimum background required for the extensive course work in specializations like hydraulic structures, sanitary and agricultural engineering, hydraulic machinery, and aeronautical and naval engineering.

The drawbacks of this development are most apparent in the education of civil engineers. Of 
the eight existing civil engineering faculties in West Germany, only three have a chair for hydraulics. The rest delegate the teaching of hydraulics to an associate professor or instructor-a person, in any case, who is dependent on, if not subordinate to, a professor of hydraulic engineering. As a matter of fact, it is not yet a thing of the past for this professor, who owes his appointment to his successful practical activity in a field such as hydrology, dams and weirs, canals and harbors, irrigation and drainage, river hydraulics, or the like, to be expected to lecture and do research in all of these fields, as well as to supervise the instruction in the fundamentals of fluid flow (Lest it be misunderstood that such centralization is confined to hydraulic engineering, it might be noted that in aeronautical engineering one could even find examples with more than one institute in the hands of one person).

With this burden of responsibility it is obvious that intensive teaching and research activity is simply not practical, and that the professional development of the junior staff, not to mention that of the professor himself, must suffer. It is not surprising, therefore, that civil-engineering students continue to learn more about rating and calculating flow processes than they learn about analyzing and understanding them. Similarly, most of their laboratory investigation shows little distinction from the kind of scale-model testing that was a pioneering achievement at the time of Engels and Rehbock but belongs to the routine today. Civil-engineering educators have yet to produce a German textbook for their students that gives a logical and concise treatise of the fundamental principles rather than an exhaustive survey of their applications. Although the undergraduate course in mechanics is part of the common engineering curriculum at most German universities, fluid mechanics (beyond hydrostatic principles) is included at only a few. At Braunschweig, for example, the civil-engineering faculty decided against a common fluid-mechanics course that had been given a short trial in conjunction with the mechanical-engineering department, on the grounds that the traditional course in hydromechanics was better correlated with the subsequent instruction in hydraulics.

The first courses in hydromechanics and hydraulics comprise, typically, 40 lecture hours plus 13 hours for solving problems. (At Darmstadt, most of the latter are being used for additional lectures in order to cover the material considered essential.) The lectures are invariably characterized by treating the inviscid fluid flows more thoroughly than the viscous, and by stressing the one-dimensional method of analysis. Selected parts of hydraulics are often taught in conjunction with their engineering applications. At Hannover, for example, pipe-flow resistance is treated together with design of water-supply systems, and open-channel flow with problems of river regulation and canal design; unsteady-flow phenomena such as water hammer and surge tanks are frequently introduced in courses on water-power engineering. Common to all course work in hydraulics has been the almost complete absence of ade- quate demonstration. But this may well be a characteristic of the past if the superbly equipped demonstration flume in one of the new classrooms at Karlsruhe is any indication of the present trend.

Despite the drastic reductions of degree requirements in recent years, engineering students still have to work out a series of design exercises. At the Karlsruhe civil-engineering department, where conditions are probably as typical as anywhere, these projects represent a work load of 1000 to 1500 hours, or 6 to 9 months, not counting the most extensive project of all, the Diplomarbeit (to be completed, theoretically, within 2 months) and the period of practical experience $(6$ months). The exercises include the design and dimensioning of a hydraulic structure, plus some extra work in hydraulics for majors in that field. As part of the latter, some flow phenomena and measuring techniques are demonstrated at current research projects during a few sessions in the laboratory which terminate class work on scale-model investigation. Although it is the goal of present efforts to use the exercise projects as means of promoting imaginative thinking and judgment, familiarizing the student with the computer, and acquainting him with laboratory experimentation, most of the projects in fact still degenerate into rather stereotyped activities of applying formulas and routine procedures to standard problems. Ironically, this has been the situation in a country where roughly 125 technical institutes are well equipped to train students for routine work in every possible engineering specialization from agricultural hydraulics to ship building, and where government officials involved in any of the numerous public hydraulic-engineering projects are required to go through an in-service program as preparation for a second state examination.

For the mechanical engineer in Germany, instruction in the mechanics of fluids took quite a different course of development. Even before Prandtl, their educators recognized the need for a new method of inquiry in place of classical hydraulics and hydrodynamics, and they were ready to adopt Prandtl's new approach in their teaching and research. Their endeavors were greatly assisted by the increasing demands of aeronautics early in this century, which helped to shape the mechanical-engineering curriculum in favor of a sound basis in fluid mechanies. As a result, a first fluid-mechanics course of at least 50 lecture hours is obligatory for all mechanicalengineering students today, plus a second of about 25 lecture hours and 25 to 50 hours of exercise for those majoring in flow-oriented specializations. In general, there is a substantial list of major courses available, from which the latter may choose such subjects as boundary-layer theory, stability and turbulence theories; flow measurement, continuum mechanics, or gas dynamics; and whereas dimensional analysis receives not even passing mention in a typical sequence of hydraulics courses, fluid-mechanics majors at Berlin are offered a complete two-credit-hour course on similitude. The only area which has been neglected in the past is that of well-balanced laboratory instruction carefully planned to permit students to verify basic 
flow principles on their own. In most departments of mechanical engineering, however, diploma candidates have the option of working on a thesis within the framework of a basic experimental research project in fluid mechanics. It is indicative of the relatively high standard of this field of specialization that its representatives will be among the first to offer a complete program of post-graduate courses at Karlsruhe, beginning in the fall of 1967 .

Among the many reforms recommended by the Wissenschaftsrat (a very influential board of government, industry, and university reprensentatives) the establishment of post-graduate study will undoubtedly have the greatest impact on German higher education. This reform will necessitate not only a revision of the entire university curriculum but also a substantial increase in the professorstudent ratio, and will thus enhance the teaching of the engineering sciences as much as that of any other basic stem of engineering education.

Because a post-graduate curriculum did not exist in the past, the tendency has been to crowd highly specialized course work into the advanced undergraduate semesters, while adhering to the traditional philosophy of giving every engineering student a broad basis in one of the main branches of engineering. With the continuously widening base of knowledge in all fields, this has led to a rather cumbersome undergraduate curriculum with the following general features : mathematics and physical sciences in the first and second year, a common core in engineering sciences starting with the second, survey courses of applications in the third and fourth, more engineering science and applications in one specific specialization toward the end, and social sciences and humanities only optionally. Under the recent regulation requiring the completion of the diploma within a certain period of time (typically 10 semesters), students tend to take seriously only what they absolutely need for passing examinations. Of the course work that is being examined, that in the specialized area plays a major role. To permit still greater specialization, the civil-engineering faculty at Darmstadt allows students to exchange up to two "examination subjects" for subjects of equivalent significance. The trouble with this freedom of choice is that the courses which thus become accessible for a student interested in, say, fluid motion, will in general be so advanced that his hydromechanics and hydraulics courses will not provide the necessary background.

Although such early specialization may well be an improvement over the traditional emphasis on breadth, its drawbacks for a sound undergraduate education in the engineering sciences are only too obvious. First, the introductory courses are too short and often too strongly oriented toward subsequent applied courses for developing a familia. rity with methods of analysis and physical reasoning. Second, there is too little room in the curricula for intermediate science courses that would make highly advanded courses useful. Third, not enough or no mathematics courses are offered in the later stages of study when their relevance to the student's degree work can be ap- preciated best. And, finally, most of the student's academic freedom has disappeared with the regimentation forcing the ambitious program into 8 to 10 semesters - a fact that is deplored by the many German educators who consider this freedom essential for fostering the acquisition of a scholarly discipline of work.

The consequences of the present curricular situation and lack of faculty positions are naturally more far-reaching for postgraduate education. Doctoral candidates are expected to proceed solely by self-study, which is little supervised and hence superficially resricted to what they consider absolutely necessary for the performance of their work. In order to secure adequate support, most of them accept an assistantship and become, in general, so overburdened with subsidiary services in their professor's administrative, academic, and consulting activities that they complete their doctorate an average of five years later than their American colleagues. Regarding their doctoral research, contact with the professor will often be so rare that the scientific if not educational value of this research is bound to suffer. Without guidance, criticism, and stimulation, the dissertation might still be an adequate means of fostering self-reliant and independent thinking; but only exceptional cases will it be a systematic contribution to the advancement of knowledge.

It is interesting to recall at this point that Prandtl's achievements in advancing fluid mechanics did not rest on his inspiring leadership alone. They were certainly effected also by the exceptionally favorable condition that he found for the formation of a group of senior staff around him. While any German professor enjoys the authority and prestige that permit uninhibited development of his capacity (but also, as practice demonstrates, uninhibited coasting), rarely is anyone so fortunate as Prandtl was with his permanent professional staff supported out of special state funds by the Kaiser-Wilhelm Society. Only recently did the universities begin to create comparable intermediate-level positions which carry tenure and independence and the Wissenschaftsrat recommend that centers of advanced study in various branches of engineering science be generously supported with both personnel and facilities. It was in line with this recommendation that the Karlsruhe civilengineering faculty decided to augment its relatively large hydraulics staff by visiting professors and the establishment of a new chair for theoryoriented fluid mechanies.

There is no doubt that this present trend will influence the teaching of the mechanics of fluids in many other respects. Decentralization and diversification will help to clear the institute atmosphere of dissension and dissatisfaction. With a larger body of faculty on all levels, professors will ultimately be in a position to utilize the existing sabbatical provision for the purpose of their owli research and continued study. They will be able to concentrate their efforts on smaller areas within their specialization and thus to intensify the guidance of and the contact with students. And exchange between related institutes, both domestic 
and foreign, will hopefully be promoted in the process; exchange programs like the one established between the Technical University of Berlin and the MIT are promising starts in that direction. In the matter of practice versus theory in hydraulics, one must only see that the pendulum does not merely swing to the opposite extreme.

With the substantial gap in manpower which war casualties and emigrations have caused, there will be a vast number of university positions that will become available to the very young as the pre-war generation retires within the next few years. It remains to be seen whether the new generation of hydraulics and fluid-mechanics teachers is prepared for the challenging tasks befor: them. If the author's impressions from his conversations with young German colleagues are any indication, and if one considers the many who have been outside of Germany for advanced study, they seem to have a clear concept about their goals. As long as they do not forget these goals once they have attained the coveted status of professor, one can be confident that they will strive to realize, against all odds imposed by the still prevailing limitations and restrictions, the very same ideals that exist in any other country.

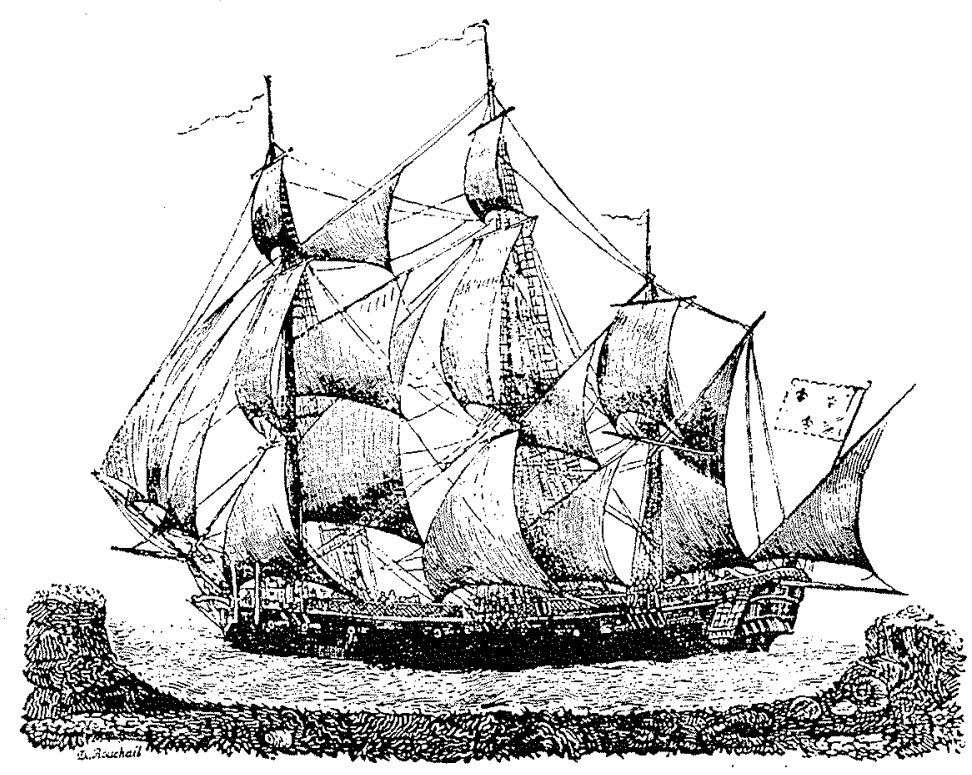

Gravure du XIX siècle 